Revista de Antropología Social

ISSN: 1131-558X

http://dx.doi.org/10.5209/rev_RASO.2016.v25.n1.52635

\title{
Colombia como territorio de belleza y violencia: ¿superando los estereotipos?
}

Jairo Tocancipá-Falla ${ }^{1}$

TAUSSIG, Michael, 2015. Belleza y Violencia: una relación por entender, Popayán: Editorial Universidad del Cauca.

De repente y aparentemente la belleza, el cuerpo, la violencia, la mutilación, el terror y la estética se conectaron. Decimos que aparentemente porque el tema no es nuevo, como lo demuestran los dos volúmenes de Umberto Eco Historia de la Belleza e Historia de la Fealdad — que Taussig no menciona- publicados en 2004 y 2007 respectivamente. Pero el trabajo de Taussig toma una vía que quiere mostrarse diferente, seguramente por temor a ser visto como defensor de las oposiciones binarias harto tratadas y reconocidas en la academia y la literatura. En su lugar, la vía preferida es escudriñar, como un cirujano ilustrado - lo que se compadece con lo que dicen muchos admiradores y no admiradores de ese suelo que se dice es Colombia-, sobre dos estereotipos ya comunes en distintos medios: la belleza y la violencia. Mientras el primero se ha exacerbado con el narcotráfico, el segundo deviene de una tradición ya conocida de violencia política en Colombia desde los años cuarenta pero potenciado en los sesenta con el boom del narcotráfico. Su estrategia de conexión, como en un sistema nervioso, es correlacionar situaciones, hechos, momentos históricos que evocan esa interrelación de la belleza con lo feo, lo terrorífico o su causante-consecuencia, la violencia. Dos líneas argumentativas sutiles se sugieren en el texto: una referida a la estética que se revela con los nuevos cambios que agencian los narcotraficantes, paramilitares — grupos militares de ultraderecha-, guerrillos — grupos armados de ultraizquierda — el mismo Estado; y la otra referida a la dinámica capitalista que se materializa con los desarrollos tecnológicos, en la forma de un consumo exagerado que asocia la expresión prestada, pero matizada, de George Bataille dépense, el arte excesivo de gastar y derrochar.

Desde la línea metodológica aparece una perspectiva de corte historicistaetnográfica, a veces muy personal y biográfica pues evoca momentos, recuerdos y fotografías desde su llegada a Colombia a finales de la década de los sesenta y que le sirven de apalancamiento para su argumento de los cambios que ha sufrido la tierra-cuerpo - léase el Valle agroindustrial en el suroccidente de Colombia-, y el mismo cuerpo, de la cabeza hasta los pies, incluidos sus accesorios como los aditamentos del cabello o las zapatillas nike que se convierten en fetiches de la nueva onda milenaria. Su operación analítica es caracterizada como "cirugía cósmica"

Universidad del Cauca

jtocancipa@unicauca.edu.co 
para aludir a esa tecnología que busca la transformación corporal y, como parte de esa expresión propia, el "dominio de la naturaleza". El desarrollo de estas líneas y esta operación transcurre en diecinueve ensayos-narrativas cortos bautizados con nombres, sugestivos unos y crípticos otros: Don de los dioses, El Mexicano, Un pájaro raro y encantador en vuelo, Winnypoo, Gastando, Chévere, La sonrisa de diseñador, El cuerpo de diseñador, Guerra mitológica, Belleza y mutilación, El seno que estalla, U virtual, La historia de la belleza, Historia del zapato, Cirujanos del bajo mundo, El nombre de diseñador, Ley en una tierra sin ley, la hendidura prohibida, El niño gordo y el diablo.

El primer texto, Don de los dioses, más que narrativa se presenta como una introducción teórica sobre la relación entre belleza, estética, consumo, violencia y muerte. En este examen, además de los consabidos antropólogos clásicos (Malinowski y Evans-Pritchard) que abordan el tema de la magia con sus consecuencias emocionales y estéticas, saca a relucir a los espadachines de siempre en su argumentación: Walter Benjamin y George Bataille. Con el primero alude a la relación entre el relato, la esperanza y la muerte; con el segundo, a la exacerbación del consumo que se traduce en la dépense. El primer "toque de dépense" empieza con El Mejicano (narcotraficante), que es contrastado con una historia truculenta y fantasiosa de este, en la cual se dice que contaba con papel higiénico que llevaba sus iniciales en oro (JGRG, José Gonzalo Rodríguez Gacha); y el segundo que, según testimonio de una guerrillera, era "vanidoso y le gustaban las buenas cosas" (p.27), entre ellas mantener una buena imagen facial que no se viera afectada por su dentadura y el acné. El segundo texto, Un pájaro raro y encantandor en vuelo, se refiere a una expresión tomada de Bataille para evocar cómo la belleza o cierto estilo de parecerse a alguien destacado, a la moda, va acompañado de dépense y referido no solo a la preocupación excesiva por gastar sino también al vacío que se siente de no hacerlo. El tercer texto, Winnypoo, es un ejercicio teórico-narrativo que busca conectar la estética de la tierra y las transformaciones que sufre por la dinámica capitalista cañera, de un lado, y el efecto del paramilitarismo con tierras arrasadas por el terror que motiva los desplazamientos, del otro. El caso de Edwin, su esposa y sus cinco hijos que huyen de Concordia (Antioquia) con sus ropas, un televisor, y cuatro osos de peluche - el grande llamado Winnypoo- es su referente.

Gastando, es una reflexión autobiográfica y teórica de cómo las cosas han ido cambiando en el mundo desde un centramiento en el hombre que satisface sus necesidades al hombre que consume. Esta "prodigalidad absurda" no es solo potestad de los que tienen sino de los que no tienen. Su apoyo ilustrativo es personal, literario y en especial teórico, basado en autores como Marx y Nietzsche. En el fondo la apuesta es cerrar el círculo del sistema capitalista, no basado en la producción, sino también en una crítica al consumo exagerado y absurdo, la dépense, que como en una espiral va generando nuevas necesidades, alienando e incrementando el deseo en hombres y mujeres de hoy. Chévere, es la antesala a los cambios que se perfilan en el ámbito de la belleza. Este capítulo se fundamenta en el Informe L, escrito por dos mujeres para determinar qué es lo chévere o la moda en boga, sin importar los efectos de la transformación y los ingresos, para los jóvenes. Se trata de la etiqueta para estar in, ganar "estilo y prestigio". La sonrisa del diseñador, es una metáfora para indicar de qué manera el Estado ha ido maquillando la realidad para ocultar otras realidades que revelan la presencia y las acciones paramilitares; algo que se asemeja a la sonrisa de Salvador Mancuso (jefe paramilitar condenado a 15 años 
y 10 meses por una jueza de la Corte del Distrito de Columbia en Washington), que también oculta otras realidades. El cuerpo del diseñador es el capítulo que da entrada a la operación estrella de la transformación del cuerpo: la liposucción y "la cirugía cósmica". A través de múltiples ejemplos, Taussig concilia la insatisfacción impulsada por los medios, la nueva imagen, la moda, el desarrollo tecnológico, etc. y la operación quirúrgica que satisface los deseos. La Guerra Mitológica introduce al lector en la estética de la cirugía cósmica que el Estado introduce a través de la moda de los uniformes que protegen al policía que pertenece al escuadrón antimotines conocido como ESMAD. Basado otra vez en Benjamin, quien anuncia que el arte de la narración está feneciendo, Taussig sugiere que, al contrario, en la moda y su socia, la tecnología, se puede apreciar el renacimiento de nuevas formas de nacer y morir. Belleza y mutilación es un texto que nos lleva a la historia política de Colombia y a la violencia partidista generada a partir de finales de la década de los cuarenta. Sin embargo, es una historia de la mutilación del cuerpo que ha tenido continuidad con los paracos y los guerrillos, quienes actúan con su terror sistemático, y dejan a la memoria para que haga el resto del trabajo con los sobrevivientes; el humor, que surge de las entrañas de tales episódicos trágicos, se revela como un "reencantamiento" de la lucha que se debe proseguir.

El seno que estalla es otro texto donde se ilustra la trama del impulso de la cirugía de los senos, los resultados inesperados y una posible explicación de por qué el fenómeno empezó a desatarse en la ciudad de Pereira donde el autor se entrevistó con varios "cirujanos cósmicos". La evocación parte de recuerdos personales de cómo antes no había preocupación y cómo de repente aparece el ímpetu por las operaciones del seno, especialmente por el sismo de 1999 que afectó al eje cafetero y que motivó la ida y retorno de muchas mujeres de la región cafetera hacia España, con lo que les permitió acceder a muchos recursos. En $U$ virtual, referido a una forma de juego infantil a las escondidas, Taussig se refiere a una joven que se ha hecho la cirugía de los senos y que trabaja en el archivo de una universidad colombiana. El juego de "ver pero no ser visto viendo tanto como ver pero no ver lo que se está viendo" (p.114), tomando como referencia el flâneur de Baudelaire, entra en escena para ilustrar el doble movimiento de la acción.

En La historia de la belleza, que creo debió llamarse historia de la moda, el autor realiza una reflexión a partir de la fotografía que muestra a algunas mujeres trabajando en los cañaduzales del Valle - con sus ropas de trabajo que se "funden" con la tierra - y del trabajo de modista que realiza su amiga Olivia Mostacilla, cuyo trabajo se va desvaneciendo por la cesión de pedidos en su labor hogareña, siendo desplazada por la tecnología y la moda de nuevas ropas que se venden por catálogos o en vitrinas de almacenes in. Historia del zapato es un recorrido desde que hombres y mujeres caminaban descalzos en los campos del valle hasta que la modernidad trajo las botas y posteriormente las buenas zapatillas para estar a la moda. Pero no solo están allí los zapatos, también las niñas y jóvenes encontraron la modernidad en el cabello adicionado - pero se ignora los nuevos cortes de cabello que no implican aditamentos sino recortes que asocian cantantes raperos - otra forma de acceder al nuevo estilo de vida. Cirujanos del bajo mundo, examina el caso de Chupeta - el hombre de las seis cirugías - cuya transformación es observada en un set de seis pequeñas fotografías de su rostro. En el fondo está el problema de la identidad trabajada no solo a través del rostro sino también mediante las huellas dactilares y donde se evocan narraciones de sustitución de dichas huellas. 
El nombre del diseñador es una prolongación del anterior capítulo y se ocupa esta vez de los nombres, los apodos y el uso del alias. El contraste incluye el caso de los paracos y guerrillos: el "Loco" Barrera, Simón Trinidad, y el propio Marulanda entre otros. Aquí, el mundo de las identificaciones falsas y los cambios corporales que buscan engañar al Estado se desplaza entre la vida y la muerte, entre el morir y el renacer. Ley en una tierra sin ley tiene semejanza con Historia de la belleza pero esta vez basada en la historia de Pepe, un sastre de Santa María de Timbiquí, poblado de la costa pacífica colombiana en el Cauca, que todavía continua trabajando en su máquina de coser y sobreviviendo al embate de la moda y los nuevos estilos de vestir. En La hendidura prohibida sigue el retorno al cuerpo con la liposucción pero esta vez detenida en su producto: la grasa, su tecnología y cierta mitología. El último capítulo del libro, El niño gordo y el diablo, busca articular el problema de fondo que asocia la belleza femenina, la violencia, la moda y el consumismo pero con un gran ausente: los pactos con el diablo que el mismo Taussig ha investigado en décadas anteriores (ver su El diablo y el fetichismo de la mercancía en Suramérica). Sin embargo el diablo no está del todo ausente pues los desastres de la cirugía cósmica no son más que una revelación de esa presencia.

En todas estas narrativas y ensayos teóricos de Taussig aparecen una serie de contribuciones analíticas y planteamientos problemáticos sobre dos estereotipos que se asocian con un país como Colombia: belleza y violencia. En primer lugar, una de las contribuciones es la idea de "conectar" hechos y eventos presentes a partir de un pasado que coexiste y permite comprender buena parte de los cambios examinados de estas dos categorías que se proyectan sobre otros dominios de la vida social. Sus vivencias en el departamento del Valle, aunque no circunscritas a este referente, le sirven de telón de fondo para vincular el estilo de vida, la moda, el proceso de agroindustrialización del valle geográfico con la fuerza de las transformaciones que trajo consigo, y en particular el dinamismo del narcotráfico, los efectos reconstructivos del sismo de 1999 ocurridos en la zona cafetera, y la violencia que se generó a partir del primero con efectos visibles en los estilos de vida, la moda y la belleza. Su ejercicio de interrelación resitúa y redimensiona crítica y "objetivamente" la noción básica de estos dos estereotipos. Se trata de una antropología del cuerpo pero no vista en términos convencionales, circunscrita al cuerpo físico al que estamos acostumbrados, sino referida a múltiples cuerpos - v. g. el cuerpo del Estado, la Madre Tierra, el cuerpo de la mujer-, que se entrelazan en y alrededor de estilos de vida y modas impuestos, resultado de la exacerbación del consumismo capitalista y su violencia resultante. La prueba fehaciente de este acto transformador y convergente es una nueva estética, ética y moral sobre la presentación del cuerpo y el ser. La segunda contribución es una conexión que revela su propia experiencia personal, y los cambios que se presentan en la región desde hace décadas. Sin ánimo de infundir un chauvinismo academicista, los investigadores criollos citados son más bien pocos, y salvo retazos de textos de Alfredo Molano y María Victoria Uribe, y unos cuantos referentes de periódicos nacionales, las argumentaciones centrales son fundamentadas en autores europeos ilustrados de las tradiciones alemana y francesa (v.g. Bataille, Baudelaire, Benjamin, Nietzsche y Marx, entre otros). La tercera contribución es que el texto suscita una serie de preguntas sobre el papel del antropólogo en su rol de traductor e intérprete crítico de la realidad social en la cual se sumerge.

El primer aspecto problemático se refiere al lenguaje y al alcance que puede tener un trabajo que se presenta en un tono críptico, con pretensiones de crítica al sistema 
capitalista. Belleza y violencia parece dirigido a un público ilustrado de académicos e intelectuales que se precian de ser críticos del sistema capitalista pero que en la práctica son otra cosa. Podría pensarse, con Taussig, que esa realidad histórica y presente es difícil de asir. Pero, ¿es posible pensar que deba ser así, que la complejidad se confunda con un lenguaje a veces enredado, confuso y hasta contradictorio? ¿A quién le puede interesar un texto que se muestra crítico de la realidad que vivimos pero que en su desenlace le atrapa a uno en referencias autobiográficas, con un estilo erudito de lectura de textos de grandes poetas, literatos y ensayistas franceses y alemanes? ¿Podría la amiga costurera de Mike, Olivia Mostacilla, que inspiró el libro, comprender la crítica que se propone? La respuesta se inclina más hacia una academia ilustrada, que se muestra crítica del sistema dentro de su propio campo referencial pero que, seguramente, teme trascender al plano de las acciones prácticas que buscan cambiar las realidades opresivas. No es para menos, pues la tarea no es nada fácil, pero por algo se debe comenzar. El traductor, el profesor Cristóbal Gnecco, parece anticipar esta lectura al adicionar el subtítulo — que no se presenta en la versión original en inglés- " Una relación aún por entender".

Quizás esté equivocado con mi interpretación del texto, al pedirle algo que no intenta decir, pero la idea se vuelve recurrente al releerlo. Tal vez, y como ocurre con su idea sugestiva de que el "estiramiento de la cara" no es tanto físico como un "estiramiento del alma", busco estirar su tejido argumentativo hacia otros dominios donde dichas contribuciones críticas se ponen a prueba. Una de las características notorias de lo que hacemos los antropólogos en un país como Colombia es formarnos y hacer academia crítica no solo para nosotros mismos, sino también para aquellos que convencionalmente llamamos grupos sociales, sociedades o movimientos sociales. Nos preocupamos por ser ilustres intérpretes de la realidad pero, a veces y tal como lo insinuó Marx - otra vez los alemanes - en sus celebradas Tesis sobre Feuerbach, nos despreocupamos por la esencia práctica de la vida social, y en especial por su transformación.

Eric Wolf en los años sesenta y Laura Nader en los ochenta sugirieron que la antropología se ve limitada, temerosa o poco interesada (?) en tratar con los asuntos del poder, del Estado - incluiría los llamados partidos políticos-, y con sus estrategias de manipulación y control, que justamente los grupos y movimientos sociales estarían interesados en conocer. Reconociendo que este interés ha cambiado en los últimos años con trabajos sobre el Estado - ver el mismo Taussig Un gigante en convulsiones o La Magia del Estado-, creo que todavía falta trabajo para trascender desde el lenguaje ilustrado de los académicos al mundo de los campesinos, trabajadores, clase media también [aunque aparentemente menos por su rating de lectura], y pueblos originarios. Pero creo que, a diferencia de Nader que sugería conocer un Estado aislado como un globo gravitando alrededor de un territorio que se dice es una nación, se trata más bien de ver las conexiones o interrelaciones como Taussig intenta hacerlo. Solo que su estilo narrativo expositivo en este libro (que contrasta con El diablo y el fetichismo de la mercancía en Suramérica), resulta ser incomprensible en muchos aspectos, "una relación por comprender". Pero quizás es un reflejo de la misma condición que se examina, una crítica que termina pareciéndose a lo que crítica: una dépense o un derroche de lenguaje, argumentos, relatos, conexiones - revelados en 19 ensayos-narrativas - que sugieren como la moda, un inicio, un fin pero un anuncio de que el análisis debe continuar: "Y ella se echó a reír" (pág. 201). 